\title{
Info-Gap Decision Theory for Assessing the Management of Catchments for Timber Production and Urban Water Supply
}

\author{
Michael A. McCarthy · David B. Lindenmayer
}

Received: 16 January 2006/ Accepted: 16 July 2006

(C) Springer Science+Business Media, Inc. 2007

\begin{abstract}
While previous studies have examined how forest management is influenced by the risk of fire, they rely on probabilistic estimates of the occurrence and impacts of fire. However, nonprobabilistic approaches are required for assessing the importance of fire risk when data are poor but risks are appreciable. We explore impacts of fire risk on forest management using as a case study a water catchment in the Australian Capital Territory (ACT) (southeastern Australia). In this forested area, urban water supply and timber yields from exotic plantations are potential joint but also competing land uses. Our analyses were stimulated by extensive wildfires in early 2003 that burned much of the existing exotic pine plantation estate in the water catchment and the resulting need to explore the relative economic benefits of revegetating the catchment with exotic plantations or native vegetation. The current mean fire interval in the ACT is approximately 40 years, making the establishment of a pine plantation economically marginal at a $4 \%$ discount rate. However, the relative impact on water yield of revegetation with native species and pines is very uncertain, as is the risk of fire under climate change.
\end{abstract}

\footnotetext{
M. A. McCarthy $(\bowtie)$

Australian Research Centre for Urban Ecology,

Royal Botanic Gardens Melbourne,

c/o The School of Botany,

The University of Melbourne, Parkville

VIC 3010, Australia

e-mail: mamcca@unimelb.edu.au

D. B. Lindenmayer

Centre for Resource and Environmental Studies,

The Australian National University,

Canberra ACT 0200, Australia
}

We use info-gap decision theory to account for these nonprobabilistic sources of uncertainty, demonstrating that the decision that is most robust to uncertainty is highly sensitive to the cost of native revegetation. If costs of native revegetation are sufficiently small, this option is more robust to uncertainty than revegetation with a commercial pine plantation.

Keywords Economic return - Info-gap decision theory $\cdot$ Stochastic model $\cdot$ Uncertainty

\section{Introduction}

It has long been recognized that the possibility of fire and other catastrophic events can influence planning decisions in forest management (Lindenmayer and others 2004). For example, in the presence of fire risk, the optimal rotation length of native forests and plantations tends to be reduced (Martell 1980; Routledge 1980; Reed and Errico 1985, 1986; Spittlehouse and Stewart 2003). If this risk of fire is sufficiently large, financial losses may be expected from forest harvesting operations, and establishing plantations may become economically unjustified. In addition to timber yields, other forest values are likely to be influenced by the occurrence of fires (Agee 1993; McCarthy and Lindenmayer 1998; McCarthy and Lindenmayer 1999; Bradstock and others 2002). For example, in the mountain ash forests of Victoria, water yield is strongly influenced by the time since the last major disturbance, be it timber harvesting or fire (O'Shaunessy and Jayasuriya 1991). Stream flow is reduced in younger forests substantially less than in older forests because of much greater rates of evapotranspiration. 
An assessment of the impact of fire risk on economic returns provides a basis for making decisions about forest management. Stochastic models that account for the risks are useful tools for management in the face of uncertainty because of the subjective judgments that are required (Burgman 2005). The usual approach to assessing fire risk in forest management is to assume a certain annual risk of fire and model the loss of forest values (e.g., destruction of standing timber) that occurs as a consequence of fires. Using stochastic models of fire occurrence, it is possible to examine how water and timber yields are likely to be influenced by different forest management regimes and to determine the optimal management policy (Martell 1980; Routledge 1980; Reed and Errico 1985, 1986; Evans 2004; McCarthy in press). Such an approach requires that both the loss of forest values in response to fire and the annual risk of fire can be determined reliably or at least probabilistically, (e.g., by placing meaningful confidence intervals on estimates based on a probabilistic model).

Planning for the risk of fire is likely to be especially important if projected changes in climate eventuate (Lenihan and others 2003; Spittlehouse and Stewart 2003). There appears to be a strong link between weather and the occurrence of fire, with annual rainfall being an especially important factor in southeastern Australia (Mackey and others 2002; Cary and others 2003; Lindesay 2003). The best available climate models predict that rainfall in the region will be reduced in the future, and such changes are likely to impact risks of fire substantially (Cary 2002). For example, in the Australian Capital Territory (ACT), the average interval between successive fires at points in the landscape is approximately 40 years, but this is predicted to halve under moderate climate change (Cary 2002). In the face of such increased risks, the possibility of financial losses from timber harvesting operations is increased.

However, in assessing the risks posed by unplanned fires, the impacts of fire on forest values and the annual risk of fire can both be difficult to estimate. Making decisions in the face of such uncertainty is problematic for the usual methods of risk assessment when uncertainty cannot be characterized probabilistically within the time available for making management decisions. For example, we might expect that the annual probability of fire will increase with climate change, but it is impossible (at this time) to characterize the uncertainty with a probabilistic model. However, nonprobabilistic uncertainty is important because decisions that ignore it are likely to lead to suboptimal outcomes.
Because of the need for making robust decisions in the face of nonprobabilistic uncertainty, Ben-Haim (2001) developed info-gap decision theory, which is suitable to situations that include nonprobabilistic uncertainty. The basis of this method is to determine the management option that is most robust to uncertainty while achieving some minimum prescribed performance requirement. The method is being used increasingly in the field of conservation biology (Regan and others 2005; Halpern and others 2006) and other disciplines (Ben-Haim 2001). Rather than optimizing the expected outcome, the info-gap approach asks how wrong can one be and still get an acceptable result. The best decision is the one that is most robust to uncertainty, by guaranteeing an acceptable outcome under the greatest degree of uncertainty.

In January 2003, fires burned a substantial proportion of the ACT, the administrative territory that surrounds Canberra, Australia's capital city (ACT Government 2003). A substantial majority of the existing pine plantations was destroyed by these fires (Bartlett and others 2005). Many of the plantation areas were located within the catchments that supply water to Canberra for domestic and commercial uses (e.g., the Lower Cotter Catchment). After the fire, revegetation is needed to protect the water catchments from erosion and other forms of environmental damage (White and others 2005). The two main options for revegetating the catchment are to use native species or the exotic Pinus radiata (Monterey pine), the main commercial plantation species used in the region (Bartlett and others 2005). Because the likelihood of environmental damage, we assumed that the management option of no action is not available in this case.

Jaakko Pöyry Consulting (2003) prepared a business plan for the ACT Government in which they recommended reestablishing approximately $80 \%$ of the forest estate as a commercial pine plantation, with the remaining area to be revegetated with native species. The business plan suggested that substantial profits would be obtained from the pine plantations. Although the plan mentioned insurance against losses from further fires (and self insurance), it did not explicitly calculate the risks of loss from fire.

In comparing the two revegetation options (native and pines), the ACT Forest business plan assumed that they would have equivalent impacts on water yield, based on a single field study in a region remote from the ACT. In contrast, modeling studies predict that revegetation with native plants is likely to lead to greater water yields than using pines (Vertessy 2001). Given the projected increases in the human population of the ACT and high demand for the water that is 
currently available, it is important to assess the sensitivity of management decisions to projected losses of water yield. On this basis, we analyze in this article the expected reduction in the financial return from pine plantations because of future unplanned fires in the ACT. We recognize that efforts will be made to reduce the occurrence of fires, but that destructive unplanned fires will continue to occur given realistic constraints on the ability of humans to control fires in extreme weather events.

We compare the two different management options by determining the effect of pines on water yield that would be necessary to make establishing pine plantations a poorer economic option compared to native forest revegetation. Because the parameters of the problem, such as the risk of fire and the effect of pines on water supply, are highly uncertain, we also analyze the problem using info-gap methods (Ben-Haim 2001). The info-gap approach to decision theory is particularly wellsuited to this decision problem because there is severe uncertainty that cannot be reliably described probabilistically within the time available for making the decision. Additionally, both options can be evaluated in terms of a single unit (in this case financial return).

The kinds of analyses we present in this article are important in a far broader context than simply the ACT water catchments and plantation forests because they are pivotal to examining conflicts over resource use. This is particularly true when there is considerable uncertainty about relevant parameters of the problem, for example, when there are little data or the future is very uncertain (e.g., when predicting impacts due to climate change). This type of uncertainty, first recognized by Knight (1921), will not be removed completely with better data or models because some types of uncertainty are persistent (Regan and others 2002). Further, better data or models will not be available for many problems within the time available for making the management decisions.

\section{Methods}

A model was developed of the costs and revenues from timber harvesting that are expected over a prescribed time period from a stand of pines in the ACT forest estate. The model is based on the financial analysis conducted by Jaakko Pöyry Consulting (2003) but also included the occurrence of unplanned fires. The influence of unplanned fires on timber yields from the pine plantation was assessed using stochastic simulation. Three thinnings prior to the final clearfelling of the pine plantation (at 30 years) are expected to
Table 1 Proposed timing and revenue of timber harvesting operations over the 30-year rotation of Pinus radiata plantations in the Australian Capital Territory (Jaakko Pöyry Consulting 2003)

\begin{tabular}{lll}
\hline Operation & Year & Revenue per ha \\
\hline First thinning & 12 & $\$ 551.70$ \\
Second thinning & 18 & $\$ 2195.16$ \\
Third Thinning & 25 & S2386.20 \\
Final Clearfall & 30 & $\$ 8744.26$ \\
\hline
\end{tabular}

provide revenue 12,18 , and 25 years after planting (Table 1 based on Jaakko Pöyry Consulting 2003).

The revenue obtained from these operations was simulated for a single stand over a 100-year time frame. The model simulated the random occurrence of fire each year as a Poisson process, with the annual risk equal to the reciprocal of the average fire interval. The average fire interval for the ACT is approximately 40 years (Cary 2002), although results were obtained from sensitivity analyses using average fire intervals ranging between 20 and 100 years. This range encompassed the projected decrease in the average fire interval in response to climate change and the range in the average fire interval across the landscape (Cary 2002).

If a fire occurred in the previous year, it was assumed in the model that the trees in the stand were killed, their value as timber was lost, and various costs were incurred such as debris removal, salvage logging, etc. Costs of removing the debris ( $\$ 1130$ per ha) were incurred in the year after all fires except for the initial year. The cost of removing debris in the initial year (2003) was not incorporated into the analysis because it was assumed that the removal of the burned timber would occur regardless of the decision to replant a $P$. radiata plantation. Costs of reestablishing the pine plantation ( $\$ 2000$ per ha) also were incurred after fire or clearfelling, with the initial replanting in 2003 incorporated into the analysis.

In the absence of fire, any revenues from thinning or clearfelling were obtained. Upon reaching the clearfelling age, the stand was cleared and replanted with $P$. radiata, with future returns obtained from a subsequent rotation of the pine plantation. Future costs and revenues were geometrically discounted at rates of 2,4 , and $6 \%$ per annum to cover a range of rates that are typically used for forest investments (Ferguson 1996). The present net value of a stand of $P$. radiata plantation was determined as the expected economic return over the next 100 years averaged over 10 million stochastic simulations of the model.

The analysis outlined above indicated the expected financial return from establishing a pine plantation and 
the sensitivity of that return to the risk of fire. However, the managers of Canberra's water catchments are faced with a decision about whether to replant a pine plantation or whether to replant with noncommercial native species (Bartlett and others 2005). Given the greater diversity of species required for native revegetation and the ready commercial availability $P$. radiata seedlings compared to many native species, the cost of replanting with native species could be greater than for $P$. radiata. Jaakko Pöyry Consulting (2003) estimated that the cost of replanting with native species is three times that of pines, and we used their figure in this analysis. However, the estimated cost of native revegetation used by Jaakko Pöyry Consulting (2003) is large compared to other estimates within Australia (Schirmer and Field 2000). The actual costs will be very sensitive to the planting density during revegetation operations. Given that there is already some natural regeneration in parts of the catchment, the cost of native revegetation is likely to be substantially reduced. Therefore, we also conducted additional analyses in which the cost of native revegetation was $\$ 2000$ and $\$ 4000$ per ha, the smaller value being approximately the cost of large revegetation projects examined by Schirmer and Field (2000) for temperate regions of Australia. After any future fires, we assumed that areas revegetated with native species would be able to regenerate without the need to expend additional resources.

One of the potential costs of the pine plantation is that the pine trees will consume more water than the native revegetation. In Canberra's water catchment, pine trees grow much more vigorously than the native vegetation (Chilvers and Burdon 1983; Burdon and Chilvers 1994), and this greater vigor may lead to greater water use. Given the seasonal variability of streamflow, estimating the relative hydrological impacts of native vegetation and pine plantations from field studies is difficult. Based on a single field study in a catchment more than $200 \mathrm{~km}$ away that did not show appreciable effects, Jaakko Pöyry Consulting (2003) assumed that pines and native vegetation would have equivalent impacts on water yield. However, Vertessy (2001), when modeling impacts of eucalypt and pine reafforestation, predicted that pine forests would yield an equivalent of $50 \mathrm{~mm}$ less annual rainfall as streamflow (for catchments equivalent to those of the ACT) than native forests.

Given the uncertainty about the effects of different vegetation on water yield, we determined the reduction in water yield that would make replanting with a commercial pine plantation less economically efficient than revegetation with native plants. To do this, we calculated the reduction in annual water yield that would be required from planting pines (relative to native revegetation) so that the present net value of the two options would be equal. In this analysis, we assumed that the value of water was $\$ 0.50 / \mathrm{kL}$, the smallest price paid by consumers after accounting for supply costs, and the future returns from water were discounted at the same rate as timber yields. We also assumed that annual maintenance costs of pines and native revegetation (e.g., weed control, recreation management) would be identical.

\section{The info-gap solution}

Although the above analyses indicated the economic viability of the pine plantation and the difference in water yield that would be necessary before it was optimal to switch between pines and native plant revegetation, it does not actually indicate the best management decision. This is because the parameters of the model are highly uncertain. In such circumstances, info-gap decision theory can find the management decision that is most robust to uncertainty (Ben-Haim 2001). Info-gap decision theory finds the management strategy that permits the greatest degree of uncertainty (possible error in the predictions) while meeting a given performance requirement. Details of the info-gap solution are provided in the Appendix, with an overview of the approach given below.

In the case of timber yield in the ACT region, one of the greatest sources of uncertainty in the expected yield is the average fire interval, which has been estimated to be approximately 40 years, but could be 20 years or less under future climate change scenarios (Cary 2002). The uncertainty in the mean fire interval $m$ can be expressed as the family of nested intervals

$$
\left|\frac{m-\tilde{m}}{\tilde{m} / 2}\right| \leq \alpha \text {. }
$$

The horizon of uncertainty $\alpha$ defines the level of uncertainty in the parameter $m$ around the nominal value $\tilde{m}$ ( $\tilde{m}=40$ in this case). For example, when $\alpha$ is $1, m$ lies within the interval $[20,60]$ years. When $\alpha$ is 2 , $m$ lies within the interval $[0,80]$ years. Because the mean fire interval must not be negative, there is the additional constraint that $m \geq 0$.

Similarly, under native forest revegetation, the annual water yield could be $50 \mathrm{~mm}(500 \mathrm{~kL} / \mathrm{ha})$ higher than under pines (Vertessey 2001), although the difference also might be negligible or even greater than $50 \mathrm{~mm}$. Therefore, the uncertainty in the increased water yield by using native forest revegetation $w$ can be 
expressed as the family of nested intervals around the nominal value $\tilde{w}(\tilde{w}=50$ in this case $)$.

$$
\left|\frac{w-\tilde{w}}{\tilde{w}}\right| \leq \alpha .
$$

In this case when $\alpha$ is $1, w$ lies within the interval $[0,100]$ $\mathrm{mm} /$ year. When $\alpha$ is $2, w$ lies within the interval $[-50$, 150] $\mathrm{mm} /$ year. A negative value for $w$ indicates that landscapes revegetated with pines yield more water than those with native plants. These models of uncertainty are used so that the relative uncertainty in $m$ and $w$ are scaled appropriately (hence the division by 2 in the denominator for mean fire interval).

The above descriptions define the uncertainty models for $m$ and $w$ (see Appendix). The next step in the infogap analysis is to define the performance function. In this example, the performance function is the expected net present value of the revenues and costs, with future values discounted geometrically. The simulation model was used to define the relationship between the average fire interval $(\mathrm{m})$ and the expected value of timber when pines were established (Fig. 1). The expected benefit of revegetating with native plants was obtained from the increased (but uncertain) water flow $w$. The extra value of water obtained from the catchment when revegetated with native plants was $\$ 5 w /$ ha/year.

Rather than trying to maximize the expected value, the info-gap approach determines robust management options that guarantee a minimally satisfactory level of performance $\mathrm{EV}_{\mathrm{c}}$. The optimal management strategy is chosen such that it maximizes the reliability of achieving this satisfactory outcome. To do this we determine, for each management option, how wrong we can be about the models (how large $\alpha$ can be in this case) but still satisfy our performance requirement $\mathrm{EV}_{\mathrm{c}}$ for all possibilities (in this case, all values of $m$ and $w$ in the intervals defined above). This maximal degree of error is termed robustness. The options can be compared graphically by plotting the robustness versus the performance requirement. By comparing the tradeoff between the performance requirement and robustness of the two management options, one can determine the management option that has the greatest robustness for a given performance requirement. In the face of severe uncertainty, the best management option is the one that is most robust.

\section{Results}

The present net value over the next 100 years of establishing the pine plantation was highly sensitive to

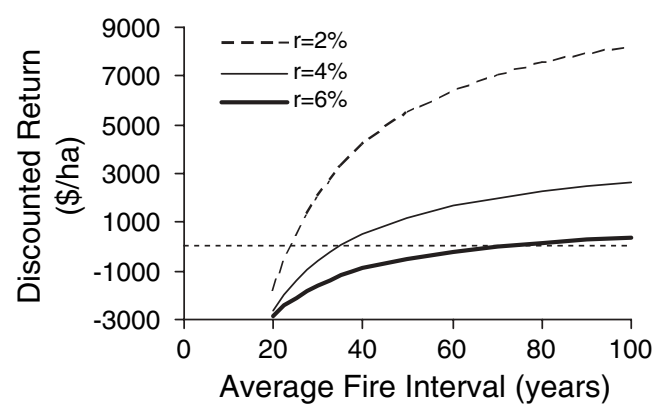

Fig. 1 Discounted return over the next 100 years of a stand of Pinus radiata versus the average time between fires for three different annual discount rates $(2 \%, 4 \%$, and $6 \%)$. The horizontal dotted line is the "break even" point at which the present net value is zero

the risk of fire (Fig. 1). At a discount rate of $4 \%$, the pine plantation is only expected to return a profit if the average time between fires is more than approximately 35 years. At a less stringent rate of $2 \%$, a profit can be expected if fires occur with an average interval of more than 25 years. However, this threshold for the average fire interval at which a profit is obtained is inflated to 70 years at a $6 \%$ discount rate (Fig. 1). Given that the average fire interval of the ACT is approximately 40 years and may be reduced to 20 years or less under climate change (Cary 2002), establishing a pine plantation in the ACT is only marginally profitable.

For the purposes of this article we estimated that there were increased costs of native plant revegetation relative to replanting with $P$. radiata, so the former option for replanting the ACT's water catchments is only economically preferable to establishing pine plantations if the pines cause a reduction in stream flow. Given the economic returns in response to different fire intervals (Fig. 1), the reduction in stream flow from pines (relative to that from native forest) would need to be greater than a specified threshold for the pines to become less profitable. This threshold is approximately $45-60 \mathrm{~mm}$ for an average fire interval of 40 years, reducing to approximately 20-35 mm for an average fire interval of 20 years (Fig. 2). These reductions are within the realm of possibility (Vertessy 2001), meaning that in the presence of the risk of fire, replanting the ACT's catchments with native vegetation may be more economically efficient than establishing pine plantations. However, if the cost of revegetating with native species was reduced or the price of water was increased beyond that assumed here, then native vegetation would be more likely to be the profitable option. For example, if the cost of revegetating with 


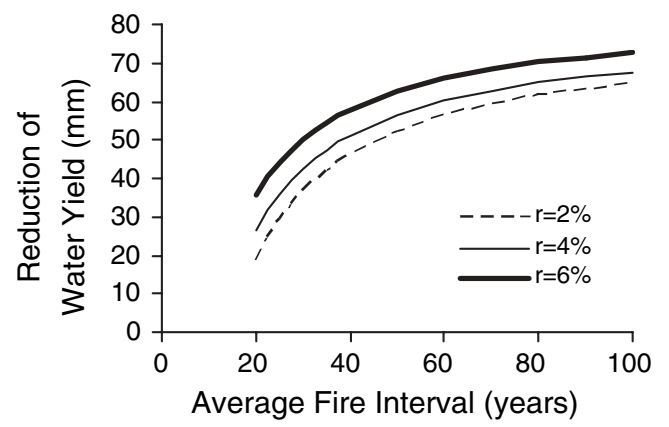

Fig. 2 Reduction in annual water yield of pines compared to native revegetation that would be necessary to make pines economically inferior to noncommercial native revegetation versus the average time between fires. The results are shown for three different annual discount rates $(2 \%, 4 \%$, and $6 \%)$

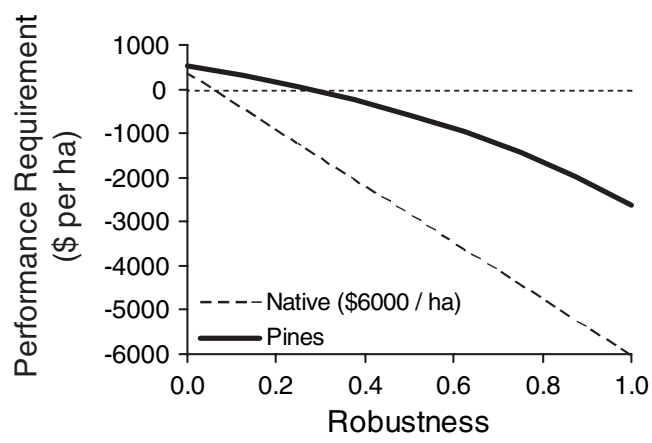

Fig. 3 The minimum performance requirement versus robustness for revegetation with pines and native plants at an annual discount rate of $4 \%$ and assuming native revegetation costs $\$ 6000$ per ha. The most robust strategy for a given level of performance is represented by the right-most of the two curves

native species was reduced to $\$ 4000$ per ha, replanting with pines becomes the less profitable option when the reduction in water yield is greater than $35-40 \mathrm{~mm}$ for an average fire interval of 40 years and $10-13 \mathrm{~mm}$ for an average fire interval of 20 years.

The most robust strategy of the two options depended on the level of performance required. If the ACT government had a requirement to at least break even with its financial investment, then revegetation with pines is most robust to uncertainty at discount rates of $4 \%$ if the cost of native revegetation is $\$ 6000$ per ha (Fig. 3). For this cost of native revegetation and over the range of discount rates considered, native revegetation only provides the greatest insurance against error if the performance requirement is to obtain at least $\$ 4000$ per ha at a $2 \%$ discount rate. Pines provided the most robust solution for other combinations of the discount rate and performance requirement. However, if costs of native plant revegetation could be reduced, then native plant revegeta-

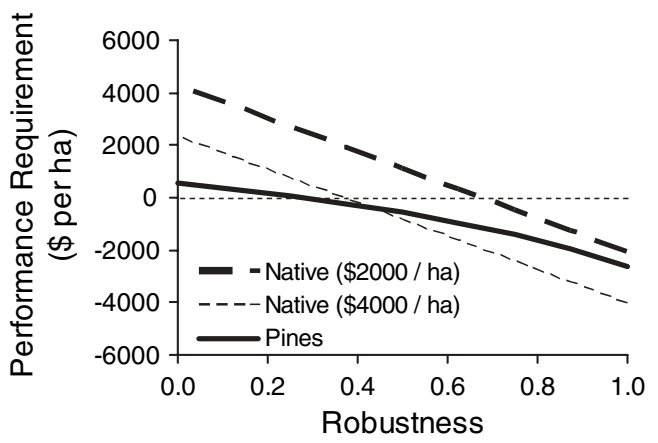

Fig. 4 The minimum performance requirement versus robustness for revegetation with pines and native plants at an annual discount rate of $4 \%$ and assuming native revegetation costs $\$ 4000$ per ha or $\$ 2000$ per ha. The most robust strategy for a given level of performance is represented by the right-most curve

tion would provide greater financial robustness than pines. The straight line representing native revegetation in Figure 3 would be raised by any saving in revegetation costs. For example, reducing native plant revegetation costs to $\$ 4000$ per ha would make the lines cross and native plants would become the most robust revegetation strategy when the aim is to at least break even financially at a $4 \%$ discount rate (Fig. 4). When costs of native plant revegetation are reduced to $\$ 2000$ per ha (the same as pines), this option is always the most robust strategy (Fig. 4). Thus, decisions about the most appropriate revegetation strategy are particularly reliant on obtaining accurate estimates of revegetation costs.

\section{Discussion}

This article demonstrates the importance of evaluating the impacts of fire risk on timber harvesting operations. For example, Jaakko Pöyry Consulting (2003) demonstrated that in the absence of fire, pine plantations are economically appealing. However, the current mean fire interval in the ACT is approximately 40 years (Cary 2002) making the establishment of a pine plantation economically marginal at a $4 \%$ discount rate (Fig. 1). Given that fires are expected to become more prevalent under even moderate climate change (Cary 2002; Spittlehouse and Stewart 2003), we predict that financial losses would be expected in the future from the proposed plantation estate.

Although the economic return of pine plantations is reduced by fire, an important question is what is the best method for revegetating Canberra's water catchments? If pines and native plants have the same impact on water yield, then pines provide the most economically effi- 
cient means of revegetation because they are cheaper to plant and provide an economic return. However, at average fire intervals of 40 years, pines would only need to reduce water yields by approximately $50 \mathrm{~mm}$ per annum compared to native revegetation to become less economically efficient. Conceivably, the difference in water yield between the two revegetation options could be negligible, as much as $50 \mathrm{~mm}$ of streamflow per year, or more (Vertessy 2001, Jaakko Pöyry Consulting 2003), placing the threshold for the management decision $(\sim 50 \mathrm{~mm})$ within the realms of possibility. A range of methods including further modeling or empirical studies are available for assessing the likely difference in water use between the two revegetation methods. However, none of these methods would remove all uncertainty and given that management decisions are required almost immediately, substantial uncertainty about the relative benefits of the different methods is likely to remain. Therefore, the info-gap approach that recognizes and assesses the uncertainty is likely to remain useful.

If the ACT Government wished to maximize the expected benefit, they would need to assess the relative likelihood of the water yield reduction being less than or greater than $50 \mathrm{~mm}$. This clearly presents the ACT government with somewhat of a dilemma because the relative impact of pines and native revegetation on water yields is very uncertain. The benefit of using an info-gap approach to the problem is illustrated in these circumstances, because the government merely needs to decide on a minimum level of performance and then determine the option that was most robust to error in meeting the required performance (Ben-Haim 2001). It is not for us to decide what this level of performance should be, given the other costs and benefits of the two options that need to be considered by the ACT Government. However, we will note that for the costs used by Jaakko Poyry Consulting (2003), pines provide the most robust strategy to breaking even financially for discount rates of between $2 \%$ and $6 \%$ (Fig. 3). However, if native plant revegetation cost only $\$ 4000$ per ha, it would become the preferred strategy.

Info-Gap

Info-gap methods differ from other non/probabilistic approaches to decision theory such as min-max (Winkler 1972) and pareto optimisation (Cohon 1978) in several ways (Ben-Haim 2001; Halpern and others 2006). First, the horizon of uncertainty in info-gap methods is unbounded while it is bounded to specified limits in, for example, min-max approaches and interval analysis. Additionally, min-max approaches focus on the expected outcome, whereas info-gap aims to maximize the robustness while guaranteeing an adequate outcome. Further more, info-gap methods can consider uncertainty in a wider range of attributes of a decision problem including parameters, model structures, probability distribution, and utilities (Ben-Haim 2001). Although info-gap methods and min-max approaches use the mathematical operators minimum and maximum, they have fundamentally different mathematical structures.

In contrast, pareto optimization and info-gap methods share a similar basis. Both consider tradeoffs between competing goals, which in the case of info-gap methods are the performance requirement and the robustness. In practice, standard pareto methods consider tradeoffs between expected outcomes of different performance parameters (such as water and timber production in this example). In contrast, info-gap methods consider tradeoffs between the performance parameters and robustness to uncertainty in the data and models. Additionally, the methods used to construct the variables in the tradeoff are fundamentally different.

\section{Caveats and Limitations}

Additional factors could be built into the analysis if information on the possible magnitude of error could be obtained. For example, future prices for both timber and water are uncertain, but could be substantially different from the values assumed here. Uncertainty in future prices has been treated probabilistically in previous studies (Brazee and Mendelsohn 1988). However, the magnitude of the uncertainty in these prices and the difficulty of making probabilistic predictions of prices decades into the future mean that an info-gap approach to this problem may be particularly useful.

Some of the other benefits that could be considered in assessing the relative merits of pines and native revegetation are biodiversity and recreation. We have not included these here because of difficulties in deriving market prices for them. It is likely that greater biodiversity benefits would be derived from native plant revegetation given that there is generally a paucity of native animal species in pine plantations compared to remnant native forests (reviewed by Lindenmayer and Hobbs, 2004). However, the biodiversity benefits of native revegetation compared to pines is largely unknown, but existing work on areas revegetated with native plants indicates that they can 
have important values for fauna of some groups of animals (e.g., birds; Kinross 2000; Greening Australia 2001; Martin and others 2004).

In this article, we assumed initially that the cost of establishing native vegetation was $\$ 6000$ per hectare. However, this may be an overestimate in a substantial proportion of the area that was burnt in 2003. For example, large numbers of Acacia trees and smaller numbers of Eucalyptus trees have germinated from soil-stored seed in some areas that formerly supported stands of $P$. radiata (M. Butz, personal communication; A. Manning and D. Lindenmayer, personal observation). The costs of revegetation with native forest in these areas may be significantly less than $\$ 6000$ per ha and may only require limited underplanting of additional Eucalyptus spp. trees. Because such planting would require a much reduced density of seedlings, the cost of revegetating these areas would be reduced substantially. As illustrated in the sensitivity analysis, if the reduction in the cost of native revegetation was sufficiently large, it would become the most economically robust option.

In the models considered in this article, fire risk did not change as a function of time since fire. However, in these forest types, the risk of fire would be expected to be low immediately after fire and increase towards an asymptote as the litter layer accumulates (McCarthy and Lindenmayer 1999). Although such changes in the risk of fire could be expected, a model of fire in the ACT region (Cary 2002) predicts a relatively rapid increase in the annual risk fire, reaching an asymptote within about 3 years (McCarthy and Cary 2002). Given that the asymptotic fire risk is reached well before the first economic returns at 12 years (Table 1), the model of a constant fire risk, although simple, is likely to provide a reasonably good approximation.

A further issue not considered in this article was the actual financial return rather than the expected return. For example, although the stand-based expected return indicates the average that would be obtained from the entire forest estate, the actual financial return from timber harvesting would depend on the actual incidence of fire across the estate. A model of this type would require information on variation in the proportion of the plantation estate that burns each year. Such considerations would increase the likelihood of the plantation yielding losses, but we were unable to determine sufficiently reliable estimates of the annual variation in fire occurrence to model the results. Similarly, we ignored annual variation in the difference in water yield between pines and native revegetation, although at least some variation would be expected. As a result, our results will tend to underestimate the true level of uncertainty in this decision problem. However, we suspect that annual variation in timber yields will be less than the annual variation in the difference in water yield, which would tend to increase the benefit revegetating with native plants.

Other differences in costs associated with pine and native revegetation such as impacts on water quality, weed control, and prescribed burning were not considered. Water quality is likely to be reduced to a greater extent (or require greater maintenance costs to ameliorate the impacts) in production forests because of the need for a wide road network to operate the plantation and high road usage (Grayson and others 1993). Pine plantations also contribute to weed invasion (especially blackberry and pine seedlings) into native remnants (Lindenmayer and McCarthy 2001), increasing costs of weed control. Furthermore, prescribed burning to reduce fuel loads and assist fire management is more difficult to achieve in pine plantations than native vegetation, meaning that costs of fire management may be greater if pines are used for revegetation rather than native species. In combination, these issues would tend to favor the use of native species for revegetation over the use of pines.

\section{Conclusion}

Because of the long time horizons involved, forest management decisions entail considerable economic risks. Probabilistic models have been developed to account for these risks in forest management, but in many cases data are not available to provide reasonable estimates for the parameters that are required. In such circumstances, it may be tempting to ignore the risks and base management decisions on deterministic analyses. However, such an approach is likely to lead to suboptimal solutions when the risks are appreciable but hard to estimate. In this article, we have shown that info-gap decision theory (BenHaim 2001) can be used to help make environmental management decisions that are robust to nonprobabilistic uncertainty.

Acknowledgments Adrian Manning kindly assisted in the collection of water price and other data that underpinned the analyses presented in this article. We are grateful to Mark Burgman, Yakov Ben-Haim, and Colin Thompson for introducing us to info-gap decision theory, and to Yakov BenHaim, Yohay Carmel, Atte Moilanen, and an anonymous reviewer for comments on the manuscript. This research was supported by the Baker Foundation's funding of ARCUE and grants by the Australian Research Council. 


\section{Appendix}

\section{Mathematical Detail of Info-gap Model}

The uncertainty models for mean fire interval $m$ and the increase in water yield $w$ can be written as

$$
U_{m}(\alpha, \tilde{m})=\{m: \max [0,(1-\alpha / 2) \tilde{m}] \leq m \leq(1+\alpha / 2) \tilde{m}\} \alpha \geq 0,
$$

and

$$
U_{w}(\alpha, \tilde{w})=\{w:(1-\alpha) \tilde{w} \leq w \leq(1+\alpha) \tilde{w}\} \alpha \geq 0 .
$$

The expected value of the timber from the pine plantation was obtained from a simulation model of fire occurrence and forest harvesting over multiple rotations (Fig. 1). The expected value was expressed as the present net value (per hectare) by discounting future revenues and costs geometrically, such that the present value (pv) of a given revenue $R$ (or cost if $R$ is negative) that is obtained $t$ years into the future is

$$
\mathrm{pv}=R /(1+r)^{t},
$$

Where $r$ is the annual discount rate (we used values within the range 0.02-0.06). The expected costs and revenues over the next 100 years were evaluated and summed to determine the net present value of the two management options. The simulation model was then used to establish the relationship between the expected present value of timber and the average interval between fires $(m)$.

The amount of water flowing from the catchment depended on the revegetation option. The annual flow of water (in mm equivalent rainfall) when the landscape was planted with pines was equal to $A$, whereas it was equal to $A+w$ when planted with native vegetation, where $w$ is the (uncertain) increase in water yield that is achieved revegetated with native plants (as defined above). Therefore, the extra volume of water obtained from the catchment when revegetated with native plants is $10 w \mathrm{~kL} / \mathrm{ha} / \mathrm{year}$. Given the value of water is $\$ 0.50 / \mathrm{kL}$, the extra value of this water is $\$ 5 w /$ ha/year. The flow of water given by $A$ is obtained regardless of the management option that is employed, so it is ignored in subsequent calculations when comparing revegetation with pines and native plants.

Rather than trying to maximize the expected value, the info-gap approach determines robust management options that guarantee a minimally tolerable level of performance $\mathrm{EV}_{\mathrm{c}}$. The optimal management strategy is chosen such that it maximizes the reliability of achieving this satisfactory outcome. This is achieved by determining, for each of the management options, how wrong we can be about the models (specifically the model parameters in this case) but still satisfy our performance requirement $\mathrm{EV}_{\mathrm{c}}$. This maximal degree of error is termed robustness. The best management strategy is the one that has the greatest robustness (ie., lets us be maximally wrong).

Once the expected value of each management strategy (EV[pine] and EV[native]) and the uncertainty model for the parameters are defined, we can then write the robustness functions $\hat{\alpha}$ for performance requirement $\mathrm{EV}_{\mathrm{c}}$ when revegetating with native plants or pines:

$\hat{\alpha}\left(\right.$ native, $\left.\mathrm{EV}_{\mathrm{c}}\right)=\max \left[\alpha: \min _{w \in U_{w}(\alpha, \tilde{w})} \mathrm{EV}[\right.$ native $\left.] \geq \mathrm{EV}_{\mathrm{c}}\right]$

$$
\hat{\alpha}\left(\text { pine }, \mathrm{EV}_{\mathrm{c}}\right)=\max \left[\alpha: \min _{m \in U_{m}(\alpha, \tilde{m})} \mathrm{EV}[\text { pine }] \geq \mathrm{EV}_{\mathrm{c}}\right]
$$

The robustness function $\hat{\alpha}\left(j, \mathrm{EV}_{\mathrm{c}}\right)(j=$ native or pine) is the maximum value of $\alpha$ (largest horizon of uncertainty) such that the minimum expected value of $\mathrm{EV}[j]$ given uncertainties in $m$ and $w$ is greater than or equal to the performance requirement $\mathrm{EV}_{\mathrm{c}}$. The robustness function is the largest degree of uncertainty that still guarantees an acceptable outcome. We then choose the option (native or pine) such that the robustness is maximized for a given performance requirement. The options can be compared graphically by plotting the robustness versus the performance requirement.

\section{References}

ACT Goveniment (2003) Shaping our territory. Final report: Opportunities for non-urban ACT. ACT Government, Canberra, Australia

Agee JK (1993) Fire ecology of the Pacific Northwest Forests. Island Press, Washington, D.C

Bartlett T, Butz M, Kanowski P (2005) Engaging the community in reforestation after the 2003 Canberra bushfire. In: Burning issues: The future of forestry, Proceedings of the Institute of Foresters of Australia National Conference, Mt. Gambier 10-14 April 2005. Institute of Foresters of Australia, Mt. Gambier, Australia

Ben-Haim Y (2000) Information-gap decision theory: Decisions under severe uncertainty. Academic Press, San Diego, California

Bradstock RA, Williams JE, Gill AM (eds) (2002) Flammable Australia: The fire regimes and biodiversity of a continent. Cambridge University Press, Cambridge, UK

Brazee R, Mendelsohn R (1988) Timber harvesting with fluctuating prices. Forest Science 34:359-372 
Burdon JJ, Chilvers GA (1994) Demographic changes and the development of competition in a native eucalypt forest invaded by exotic pines. Oecologia 97:419-423

Burgman MA (2005) Risks and decisions for conservation and environmental management. Cambridge University Press, Cambridge, UK

Cary GJ (2002) Importance of changing climate for fire regimes in Australia. In: Bradstock RA, Williams LE, Gill AM (eds) Flammable Australia: the fire regimes and biodiversity of a continent, Cambridge University Press, Cambridge, UK

Cary G, Lindenmayer DB, Dovers S (eds) (2003) Australia burning. CSIRO Publishing, Melbourne, Australia

Chilvers GA, Burdon JJ (1983) Further studies on a native Australian eucalypt forest invaded by exotic pines. Oecologia 59:239-245

Cohon JL (1978) Multiobjective programming and planning. Academic Press, NewYork

Evans C (2004) Assessing the effects of fire on management of mountain ash (Eucalyptus regnans) forests. B. Sc. Honours Thesis, The University of Mebourne, Parkville, Australia

Ferguson IS (1996) Sustainable forest management. Oxford University Press, Melbourne, Australia

Grayson RB, Haydon SR, Jayasuriya MDA, Finlayson BL (1993) Water-quality in mountain ash forests-separating the impacts of roads from those of logging operations. J Hydrol 150:459-480

Greening Australia (2001) Bringing birds back. A glovebox guide for bird identification and habitat restoration in ACT and SE NSW. Greening Australia, ACT and SE NSW, Australia

Halpern B, Regan H, Possingham HP, McCarthy MA (2006) Accounting for uncertainty in marine reserve design. Ecol Lett 9:2-11

Jaakko Pöyry Consulting (2003) ACT forests reforestation business case. Consultant report for the ACT Department of Urban Services, Canberra, Australia

Kinross CM (2000) The ecology of avian communities of farm windbreaks. Ph.D. thesis, Charles Sturt University, Bathurst, N.S.W

Knight FH (1921) Risk uncertainty and profit. Houghton, Mifflin Co., reissued by Beard Books, Washington, DC, (2002)

Lenihan JM, Drapek R, Bachelet L D, Neilson RP (2003) Climate change effect on vegetation distribution, carbon, and fire in California. Ecol Applic 13:1667-1681

Lindenmayer DB, Hobbs RJ (2004) Biodiversity conservation in plantation forests-a review with special reference to Australia. Biol Conserv 119:151-168

Lindenmayer DB, McCarthy MA (2001) The spatial distribution of non-native plant invaders in a pine-eucalypt landscape mosaic in south-eastern Australia. Biol Conserv 102:77-87

Lindenmayer DB, Foster D, Franklin JF, Hunter M, Noss R, Schiemegelow F, Perry D (2004) Salvage harvesting after natural disturbance. Science 303:1303

Lindesay J (2003) Fire and climate in Australia. In: Cary G, Lindenmayer DB, Dovers S (eds) Australia burning. CSIRO Publishing, Melbourne, Australia, pp 32-40

Mackey B, Lindenmayer D, Gill M, McCarthy M, Lindesay J (2002) Wildfire, fire \& future climate: a forest ecosystem analysis. CSIRO Publishing, Collingwood, Australia
Martell DL (1980) The optimal rotation of a flammable forest stand. Can J For Res 10:30-34

Martin WK, Eyears-Chaddock M, Wilson BR, Lemon J (2004) The value of habitat reconstruction to birds at Gunnedah, New South Wales. Emu 10:177-189

McCarthy MA (in press) Using models to compare the ecology of cities. In: McDonnell MJ, Hahs A (eds) Comparative ecology of cities and towns. Cambridge University Press, Cambridge, UK

McCarthy MA, Lindenmayer DB (1998) Multi-aged mountain ash forest, wildlife conservation and timber harvesting. Forest Ecol Manage 104:43-56

McCarthy MA, Lindenmayer DB (1999) Incorporating metapopulation dynamics of greater gliders into reserve design in disturbed landscapes. Ecology 80: 651-667

McCarthy MA, Cary GJ (2002) Fire regimes in landscapes: models and realities. In: Bradstock RA, Williams JE, Gill AM (eds) Flammable Australia: The fire regimes and biodiversity of a continent. Cambridge University Press, Cambridge, UK

O'Shaughnessy P, Jayasuriya J (1991) Managing the ash-type forest for water production in Victoria. In: McKinnell FH, Hopkins ER, Fox JED (eds) Forest management in Australia. Surrey Beatty and Sons, Chipping Norton, Australia

Reed WJ, Errico D (1985) Assessing the long-run yield of a forest stand subject to the risk of fire. Can J For Res 15:680 687

Reed WJ, Errico D (1986) Optimal harvest scheduling at the forest level in the presence of the risk of fire. Can J For Res 16:266-278

Regan HM, Colyvan M, Burgman MA (2002) A taxonomy and treatment of uncertainty for ecology and conservation biology. Ecol Applic 12:618-628

Regan HM, Ben-Haim Y, Langford B, Wilson WG, Lundberg P, Andelman SJ, Burgman MA (2005) Robust decision making under severe uncertainty for conservation management. Ecol Applic 15:1471-1477

Routledge RD (1980) The effect of potential catastrophic mortality and other unpredictable events on optimal rotation policy. For Sci 26:389-399

Schirmer J, Field J (2000) The cost of revegetation. Department of Environment and Heritage Report, Canberra, Australia

Spittlehouse DL, Stewart RB (2003) Adaptation to climate change in forest management. BC J Ecosystems Manag 4:111

Vertessy RA (2001) Impacts of plantation forestry on catchment runoff. In: Nambiar EK, Brown AG (eds.) Plantation, farm forestry and water. Proceedings of a national workshop, RIRDC report no. 01/20, Melbourne, Australia pp 9-19

White I, Govinnage-Wijesekera D, Worthy M, Wade A, Wasson R, Mueller N (2005) Impacts of the January 2003 bushfires on water supplies in the Australian, Capital Territory. In: Proceedings 29th Hydrology and Water Resources Symposium. Engineers of Australia, Canberra, Australia

Winkler RL (1972) An introduction to Bayesian inference and decision. Holt, Rinehart and Winston, New York 